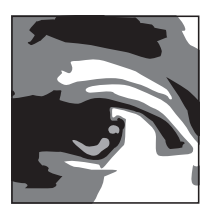

\title{
To Stay or Go? The Complexities of Providing Healthcare in Insecure Environments
}

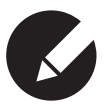

Larissa Fast, PhD, Fellow, American Association for the Advancement of Science, Washington, DC.

Christina Wille, MPhil, Director, Insecurity Insight, Vevey, Switzerland.

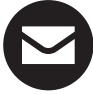

Correspondence may be directed to:

Larissa Fast

E-mail: larissafastphd@gmail.com

On June 17, 2014, an aerial attack on a

Sudanese village severely damaged a hospital operated by the international medical humanitarian organization Médécins Sans Frontières (MSF) in the war-affected region of South Kordofan (MSF 2014). The bombs injured a staff member and destroyed the emergency room, the pharmacy and the hospital kitchen. Hospitalized patients had to be evacuated (MSF 2014). On January 20, 2015, a cluster of 13 bombs was dropped on the same hospital. Two landed within the hospital compound and injured a staff member and a patient. Others struck just outside the hospital compound (MSF 2015).
After the first incident, MSF continued to work in the damaged premises but reported that the bombing had hampered the effectiveness of its work (MSF 2014). After the second bombing, the organization suspended its work. The second incident caused limited physical damage to the hospital, but MSF halted activities to avoid putting staff and patients at risk (MSF 2015). In West Africa, Red Cross and other healthcare providers working to educate and provide care in Ebola-affected communities were attacked and killed, exacerbating the challenges of eradicating the virus that has taken more than 10,000 lives (Izadi 2014). 
These examples illustrate how many healthcare providers are compelled to withdraw or temporarily close their programs when violence intensifies. This has devastating consequences for the civilian populations who often have few available alternative healthcare options.

The lethal consequences of war and conflict on the health of civilians are well documented and last well beyond the end of the fighting. Indirect deaths from war and armed conflict, resulting from war-related disease and malnutrition and not violence, surpass deaths on the battlefield (Human Security Report 2010). A study examining mortality rates in the Darfur conflict in Sudan pointed to decreased mortality from violence and to increased mortality from indirect causes among populations with more internally displaced persons. Moreover, the higher rates of mortality corresponded to periods with reduced humanitarian presence, caused by both funding constraints and insecurity (Degomme and Guha-Sapir 2010). The destruction of health infrastructure, such as clinics and hospitals, the looting of supplies and equipment and the deaths of healthcare workers themselves all exacerbate the death toll from reduced access to healthcare long after the violence stops (Kruk et al. 2009). The lack of adequate healthcare is one reason why mortality rises dramatically during violent conflict. In the Democratic Republic of Congo, babies born to mothers displaced by violence die from lack of adequate medical care. Access to basic and clean supplies and trained healthcare workers can significantly reduce maternal mortality rates, even in the midst of violent conflict (UNFPA 2011).

Clearly, continued healthcare provision during periods of intensified violence is crucial to reducing mortality rates during war or armed conflict. The consequences for civilians are generally well known, even if country-specific mortality rates remain difficult to accurately quantify, as are the types of risks that health providers face.
Less-well documented, and therefore understood, are the decisions health providers make in response to actual or anticipated violence and insecurity and the reasons for these decisions. As the South Kordofan and West Africa examples above illustrate, substantial risks often accompany the provision of healthcare.

The risks and challenges of providing healthcare in the midst of violence are myriad. From Afghanistan to South Kordofan, health facilities and infrastructure have been damaged. The patients and their families are also not immune. The MSF documented at least 58 cases of patients being killed in hospitals in South Sudan over a six-month period in 2014 (Batha 2014). In Iraq in June 2014, a car bomb killed 14 people when it exploded outside a hospital and in front of a café frequented by relatives of patients (Reuters 2014). Doctors in Somalia and Syria have been deliberately targeted and killed. In December 2013, for instance, one Somali and three Syrian doctors were ambushed and killed by unknown assailants (BBC 2013). In Nigeria and Pakistan, vaccinators and their escorts have been shot and killed while attempting to vaccinate children against polio.

Non-lethal attacks on healthcare providers and services also present significant challenges. Medical personnel have been kidnapped in Yemen (Al-Arabiya News/Reuters 2014), harassed and threatened in Nepal (IRIN 2014b) and expelled in Burma (IRIN 2014a). They have been targeted and attacked while helping protestors in Ukraine and Bahrain (HRW and Safeguarding Healthcare 2014). In Afghanistan, military personnel have stopped medical staff on their way to provide healthcare to civilians (Terry 2010). The campaigns to safeguard healthcare and protect those providing life-saving health services in the midst of conflict are indispensable for advocacy efforts to raise awareness of these challenges and their cost for both healthcare providers and the affected civilian populations (Box 1). 


\section{Box 1: Advocacy Campaigns}

A number of separate yet complementary campaigns focus on violence against healthcare providers:

- Medical Care Under Fire (Médecins Sans Frontières):

articles and updates about threats and attacks against healthcare providers and facilities in selected countries. $<w w w . m s f . o r g / t o p i c s / m e d i c a l-c a r e-u n d e r-f i r e>$ - Physicians for Human Rights: documents persecution of health workers in Bahrain, Iran and Syria. Interactive map of Syria available at: <https://s3.amazonaws.com/ PHR_syria_map/web/index.html>

- World Health Organization (WHO) is developing a monitoring system on attacks on healthcare infrastructure: advocates work on the protection of healthcare infrastructure.

- Safeguarding Health in Conflict Coalition: produces an annual report to highlight the issue; works to strengthen the mechanisms for monitoring, reporting and accountability. See <www.safeguardinghealth.org/>.

- Healthcare in Danger campaign (International Committee of the Red Cross): documents incidents and promotes practical solutions. See <www.icrc.org/eng/what-we-do/ safeguarding-health-care/>.

Yet, why do healthcare providers decide to remain in some situations and to withdraw in others? Do some types of attacks more often result in staff evacuation or program closures? A complex interplay between a variety of factors influences whether and why healthcare providers either close or choose to maintain services in the face of threats or insecurity. In some cases, healthcare providers withdraw in anticipation or fear of violence. In Mali in February 2012, Médécins du Monde withdrew its staff and suspended its operations due to insecurity, indicating that the conflict preventing them from delivering services safely and effectively. Local health workers also fled the violence, leaving civilians who remained without access to healthcare (Fominyen 2012). In other cases, the fear of violence is related to the threat of violence or past experiences. For example, in Baluchistan, Pakistan, in 2004, several humanitarian healthcare providers suspended activities due to anticipated suicide attacks in the area (IRIN 2004). Similarly, the International Federation of the Red Cross suspended activities in Chad in 2008 due to a serious security threats (Reuters 2008).
To more effectively respond, we need more research on how types of violence, threats of violence and perceptions of violence influence agency decisions to either stay or go. The Insecurity Insight Security in Numbers Database (SiND) $)^{1}$ and Aid in Danger project have the potential to contribute to a better understanding of these issues. The database has already compiled over 15 years of data about the effects of insecurity on humanitarian organizations and their operations, taken from public sources, such as media reports, and directly reported information from participating organizations. This includes the effects on health programs. ${ }^{2}$ The events affecting the delivery of healthcare and healthcare services include a range of event types, from attacks on doctors, nurses or ambulances to armed intrusions into healthcare facilities. Specific information about these events, however, is kept confidential to protect the identity of affected providers and to ensure that public discussion of this issue does not further hamper the ability of these actors to provide healthcare.

The underlying database contains information about victims, perpetrators and damage to infrastructure, as well as the weapon used in an event. The information can be used to examine and compare attacks on different types of healthcare providers (e.g., local hospitals and international agencies) or to examine morbidity and mortality resulting from different types of attacks. It has the potential to compare non-state actors with government actors and to examine the types of attacks each commits against health programs, to test theory and commonly held assumptions about these types of violence. Crucially, the SiND also includes information about measures taken in response to either actual or anticipated violence and how this affects the provision of services. Thus, the information in the SiND makes it possible to identify patterns in the responses of healthcare providers, 
and therefore, to better anticipate the effects of these decisions on local populations. ${ }^{3}$

As the root causes of the reduction in healthcare services are the result of the complex interplay of types of violence and destruction, the threat of force and fear of violence, the data set has the potential to provide important new insights about differences in the magnitude of damage and in responses over time across contexts. The information contained in the SiND can assist in raising awareness about the problems and in generating a better understanding of where and when agencies decide to stay or go in response to or in anticipation of violence.

The SiND is one component of what is already a broader effort to investigate violence against healthcare providers. Initiatives to document the types and occurrence of violence are indispensable in raising awareness and providing essential information about the scope of the problem. The MSF Medical Care under Fire project examines selected contexts in depth and provides information on crises as they develop. ${ }^{4}$ Physicians for Human Rights documents persecution of health workers in Bahrain, Iran and Syria and runs an interactive map of incidents that affect healthcare in Syria. ${ }^{5}$ The World Health Organization (WHO) is developing a monitoring system on attacks on healthcare infrastructure and advocates for the protection of healthcare infrastructure. The Safeguarding Health in Conflict Coalition highlights the global issue in an annual report and seeks to strengthen mechanisms for monitoring, reporting and accountability. ${ }^{6}$ The Red Cross Movement's Healthcare in Danger campaign focuses on documenting incidents and promoting practical solutions, with its "Towards Solutions" publications. ${ }^{7}$ Country-level studies, such as those by researchers in Burma (Footer et al. 2014), document the specific threats and security management innovations that healthcare providers use in situations of violent conflict and can give voice to the local staff whose perspectives are often neglected. Each of these initiatives is complementary. Yet additional approaches and methods are also needed to advance our understanding of the ways to better protect healthcare providers and facilities during armed conflict. In-depth case studies of specific decision-making processes and outcomes would shed light on the reasons for a decision to stay and the subsequent effects on staff and patients, thereby helping to answer the question of what leads agencies to either stay or go. Together, such a body of research will build the evidence base to develop appropriate and effective policies to safeguard healthcare in contexts of violence.

\section{Notes}

1. The authors are the co-founders and principal researchers of the SiND project.

2. These events will be visualized on the Aid in Danger project website: $<$ http://aidindanger.org $>$.

3. For more information, or to become a project partner, contact Christina Wille, $<$ christina.wille@insecurityinsight.org $>$ or Larissa Fast, <larissafastphd@gmail.com $>$.

4. <www.msf.org/topics/ medical-care-under-fire $>$.

5. <https://s3.amazonaws.com/PHR_syria_map/web/index.html $>$.

6. <www.safeguardinghealth.org/>.

7. <www.icrc.org/eng/what-we-do/ safeguarding-health-care/>.

\section{References}

Al-Arabiya News/Reuters. 2014 (February 23). "Gunmen Kidnap Czech Woman Doctor in Yemen.” Retrieved May 16, 2016. <http://english. alarabiya.net/en/News/middle-east/2014/02/23/ Gunmen-kidnap-Czech-woman-doctor-inYemen.html>

Batha, E. 2014 (July 1). "At least 58 People Killed in South Sudan Hospitals-MSF." Thomson Reuters Foundation. Retrieved May 16, 2016. <www. trust.org/item/20140630163437-ogfrv\%20 (COPY)\%20(COPY)> 
BBC. 2014 (December 18). 'Syrian and Somali Doctors' Shot Dead Near Mogadishu. Retrieved May 16, 2016. <www.bbc.com/news/worldafrica-25428515>.

Degomme, O. and D. Guha-Sapir. 2010. "Patterns of Mortality Rates in Darfur Conflict." The Lancet 375(9711): 294-300.

Fominyen, G. 2012 (February 7). "Medecins du Monde Halts Work in North Mali Amid Fighting." AlertNet. Retrieved May 16, 2016. <www.trust. org/alertnet/news/medecins-du-monde-haltswork-in-north-mali-amid-fighting/>.

Footer, K.H.A, S. Meyer, S.G. Sherman and L. Rubenstein. 2014. "On the Frontline of Eastern Burma's Chronic Conflict: Listening to the Voices of Local Healthcare Workers." Social Science \& Medicine 120: 378-86.

Human Rights Watch and Safeguarding Health in Conflict. 2014. Under Attack: Violence Against Health Workers, Patients and Facilities. New York: Human Rights Watch and Safeguarding Health in Conflict.

Human Security Report Project. 2010. Human Security Report 2009/2010: The Causes of Peace and the Shrinking Costs of War. New York and Oxford: Oxford University Press and Simon Fraser University, Human Security Report Project.

IRIN. 2004 (June 7). "Pakistan: Threat to Aid Agencies Not 'Specific.'” Islamabad, Pakistan. Retrieved May 16, 2016. <www.irinnews.org/ print.asp? ReportID=41448>.

IRIN. 2014a (March 3). "Myanmar Still Talking Tough Over MSF Expulsion from Rakhine." Yangon, Myanmar. Retrieved May 16, 2016. <www.irinnews.org/report/99736/myanmar-stilltalking-tough-over-msf-expulsion-from-rakhine> .

IRIN. 2014b (March 21). "Rude Health - Fear and Violence in Nepal's Medical System.” Kathmandu, Nepal. Retrieved May 16, 2016 . <www.irinnews. org/printreport. aspx? reportid $=99818>$.
Izadi, E. 2014 (September 24). "Red Cross Volunteers Attacked in Guinea while Trying to Bury Ebola Victim." The Washington Post. Retrieved May 16, 2016. <www.washingtonpost. $\mathrm{com} /$ news/to-your-health/wp/2014/09/24/ red-cross-volunteers-attacked-in-guinea-whiletrying-to-bury-an-ebola-victim/>.

Kruk, M.E., P.C. Rockers, E.H. Williams, S.T. Varpilah, R. Macauley, G. Saydee and S. Galea. 2009. "Availability of Essential Health Services in Post-Conflict Liberia." Bulletin of the World Health Organization 88: 527-34. Retrieved May 16, 2016. <www.who.int/bulletin/volumes/88/7/09071068/en/\#>

Médécins Sans Frontières. 2014 (June 17). "MSF hospital bombed in Sudan: Amidst Bombing of South Kordofan village, MSF Facility Attacked." MSF Press Release. Retrieved May 16, 2016. $<$ www.msf.org/article/msf-hospital-bombedsudan>.

Médécins Sans Frontières. 2015 (January 22). "Sudan: MSF Hospital Bombed in South Kordofan.” MSF Press Release. Retrieved May 16, 2016. <www.msf.org/article/sudan-msf-hospitalbombed-south-kordofan $>$.

Reuters. 2008 (July 3). "Red Cross Aid Workers Leave Chad after Threat." Retrieved May 16, 2016. <www.alertnet.org/thenews/newsdesk/ L03419779.htm>.

Reuters. 2014 (June 14). "Iraq Hospital Bombing Kills 14.” Retrieved May 16, 2016. <www.reuters.com/article/2014/06/04/us-iraqsecurity-idUSKBN0EF27E20140604>

Terry, F. 2010. "Protection of Health Care in Afghanistan: IHL Violations and the ICRC's Response (April 2009-April 2010).” International Committee of the Red Cross.

UNFPA. 2011 (September 19). "Dispatch: Working Against All Odds to Improve Maternal Health in DRC.” Retrieved May 16, 2016. <www. unfpa.org/public/home/news/pid/8388>. 